\title{
Investigation on Structural and Optical Properties of ZnO Film Prepared by Simple Wet Chemical Method
}

\author{
Amalia Sholehah ${ }^{1,2, a}$, Rendi Mulyadi ${ }^{1,2}$, Didied Haryono ${ }^{1,2}$, Imamul Muttakin ${ }^{1,3}$, \\ Tb Bahtiar Rusbana ${ }^{4}$, Mardiyanto $^{5}$ \\ ${ }^{1}$ Advanced Material and Tomography Laboratory, Faculty of Engineering, Universitas Sultan Ageng Tirtayasa , \\ Jl. Jenderal Sudirman Km 3, Cilegon - Banten 42435, Indonesia \\ ${ }^{2}$ Department of Metallurgical Engineering, Faculty of Engineering, Universitas Sultan Ageng Tirtayasa, \\ Jl. Jenderal Sudirman Km 3, Cilegon - Banten 42435, Indonesia \\ ${ }^{3}$ Department of Electrical Engineering, Faculty of Engineering, Universitas Sultan Ageng Tirtayasa, \\ Jl. Jenderal Sudirman Km 3, Cilegon - Banten 42435, Indonesia \\ ${ }^{4}$ Departement of Sustainable Agriculture, Faculty of Agriculture, Universitas Sultan Ageng Tirtayasa, \\ Jl. Raya Jakarta Km 4, Serang - Banten 42124, Indonesia \\ ${ }^{5}$ National Nuclear Energy Agency of Indonesia, Kawasan Puspiptek Serpong, Gedung 71, \\ Tangerang - Banten 15310, Indonesia \\ a)Corresponding author: amalia.sholehah@untirta.ac.id
}

\begin{abstract}
ZnO thin layer has a broad potential application in electronic and optoelectronic devices. In this study, vertically align ZnO layers were deposited on ITO glass using wet chemistry method. The seed layers were prepared using electrodeposition technique at $3^{\circ} \mathrm{C}$. The growing process was carried out using chemical bath deposition at $90^{\circ} \mathrm{C}$. To improve the structural properties, two different hydrothermal treatment variations were applied separately. From the experiment, it is shown that the hydrothermal process using $\mathrm{N}_{2}$ gas has given better results, compared to the conventional treatment.
\end{abstract}

\section{INTRODUCTION}

Recent development of optoelectronic devices in modern daily life has been increasing. As a result, researchers are forced to develop low-cost semiconductor materials and production methods. It is commonly kown that the price of nanostructured optoelectronic devices in today's technological world is highly depending on the nanostructure growth technologies and the cost of materials. As a wide band gap $(3.37 \mathrm{eV})$ semiconducting oxide with a large excitons binding energy $(60 \mathrm{meV})$ at room temperature, nanostructured zinc oxide $(\mathrm{ZnO})$ has triggered extensive interest due to its unique advantages, such as large surface area, enhanced light scattering capacity and high porosity (Yang, Wang, Kong, Jia, \& Wang, 2015). One-dimensional (1D) ZnO nanostructure has been one of the most popular topics in material, chemistry and physics due to its great potential in electronics and optoelectronics application, such as solar cells (Lizama-Tzec et al., 2016), light emitting diode (Jo et al., 2005) and sensing devices (Shao, Chang, \& Long, 2014). Although many of the research efforts are still concentrate in the preparation of 1D $\mathrm{ZnO}$ without concening the growth direction, it has been realized that the construction of nanostructures in a wellordered alignment and morphology, is critical for scientific and technological applications. Until now, many technologies have been utilized in $\mathrm{ZnO}$ synthesis and fabrication, such as chemical vapor deposition (CVD) (Duan et al., 2015), spray pyrolisis (Shinde, Bhosale, \& Rajpure, 2013), wet chemical (Vanalakar et al., 2015), and laser deposition method (Hong, Bae, Wang, \& Snyder, 2009). Among them, wet chemistry route has proven to be one of the most efficient method due to its convinience and low cost process. In this work, $\mathrm{ZnO}$ is prepared using the 
combination of electrodeposition, chemical bath deposition (CBD), and hydrothermal method. The structural and optical informations of $\mathrm{ZnO}$ obtained are characterized and discussed afterwards.

\section{EXPERIMENTAL METHODS}

The seeding solution was prepared by dissolving zinc nitrate tetrahydrate $\left(\mathrm{Zn}\left(\mathrm{NO}_{3}\right)_{2} \cdot 4 \mathrm{H}_{2} \mathrm{O} / \mathrm{Zn}\right.$-nitrate, Merck) and heksametilentetraamin $\left(\mathrm{C}_{6} \mathrm{H}_{12} \mathrm{~N}_{4} / \mathrm{HMTA}\right.$, Merck) in $0^{\circ} \mathrm{C}$ and being aged for an hour. The concentration of seeding solution was fixed at $0.1 \mathrm{M}$. The indium tin oxide $\left(\mathrm{InSn}_{2} \mathrm{O}_{3}\right.$, ITO) glass was cleaned in water, acetone, and ethanol with ultrasonic cleaner for 480 seconds in each liquid. After that, the ITO glass was dried and stored in a dry place. The electrodeposition system was constructed using ITO glass as the anode and Pt coated Ti wire mesh as the cathode. The experiment was conducted using voltage of $-2.5 \mathrm{~V}$ for 1 hour in cold bath $\left(3^{\circ} \mathrm{C}\right)$, until white, thin seeding layer was seen on top of the ITO glass. The growing process was conducted by chemical bath deposition (CBD). The seeded ITO glass was placed vertically in $0.05 \mathrm{M}$ Zn-nitrate and HMTA solution at $90^{\circ} \mathrm{C}$ for 3 hours. The as-synthesized $\mathrm{ZnO}$ layers were subsequently separated into two groups. The first group was subjected to treatment in hydrothermal reactor at a temperature of $150^{\circ} \mathrm{C}$ for 3 hours at atmospheric pressure. This hydrothermal treatment was further referred by the acronym HT-1. The second group was hydrothermal process using closed reactor at $100^{\circ} \mathrm{C}$ for 1 hour under 1 bar nitrogen gas $\left(\mathrm{N}_{2}\right)$ pressure. This treatment was referred by the acronym HT2. The hydrothermal process was carried out by steaming the as-synthesized $\mathrm{ZnO}$ layers above water in container with capacity of $50 \mathrm{~mL}$. For each process, the sample collected was further washed with distilled water, dried, and characterized afterwards. The morphology of the obtained $\mathrm{ZnO}$ nanorods was examined using field-emission scanning electron microscopy (FE-SEM, FEI - Quantana 650), while the crystal's structural information was gained using X-ray diffraction (XRD, Pan Analytical X-Pert Pro) at room temperature with $\mathrm{Cu} \mathrm{K \alpha}$ radiation $(\lambda=1.54 \AA)$. Optical information of the samples were gained using ultraviolet-visible spectrophotometer (UV-VIS Spectrophotometer, Shimadzu 2450) in diffuse reflectance spectroscopy (DRS) mode.

\section{RESULTS AND DISCUSSION}

The $\mathrm{ZnO}$ layer was prepared using 3 steps, ie. seeding, growing, and orienting process. As shown in Figure 1, most of the $\mathrm{ZnO}$ were grown in nanorods structure. However, compared to the as-synthesized and HT-1 treatment, the addition of $\mathrm{N}_{2}$ pressure in HT-2 treatment has given a smaller nanostructure diameter (Fig. 1.c). This is considered as the effect of the gas pressure which forcing the bundling nanorods structure to separate. As a results, the $\mathrm{ZnO}$ diameter tend to look smaller with good coverage on top of the substrate. In Fig. 2, it is appeared that the ZnO layer has grown in vertical align. However, HT-2 treatment has developed a smoother and denser ZnO layer, as shown in Fig. 2.c. The addition of $\mathrm{N}_{2}$ gas can minimize the structural damage during orientation process, thus generating better $\mathrm{ZnO}$ layer. The diameter and thickness of $\mathrm{ZnO}$ layers are presented in Table 1.

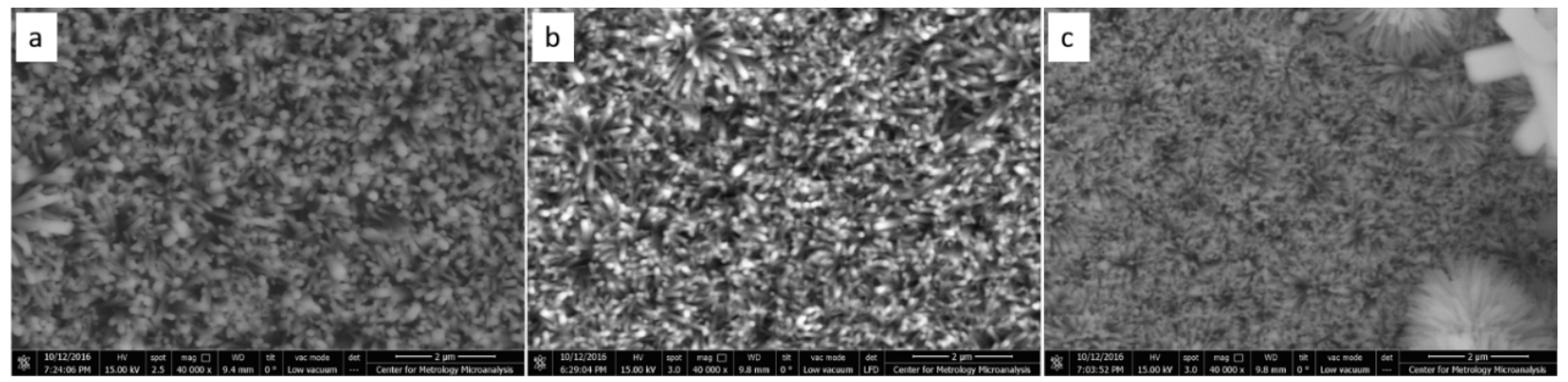

FIGURE 1. . Top view of ZnO layer on ITO with magnification of 40.000x a) as-grown with CBD method, b) after HT-1 treatment, c) after HT-2 treatment 

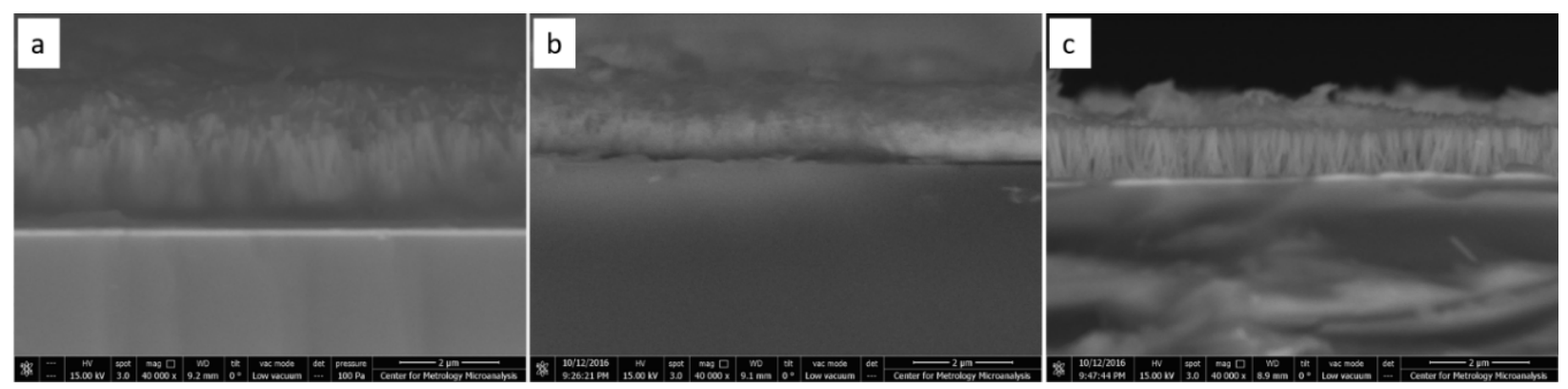

FIGURE 2. Cross-sectional view of $\mathrm{ZnO}$ layer on ITO with magnification of 40.000x a) as-grown with CBD method, b) after HT-1 treatment, c) after HT-2 treatment

TABLE 1. Diameter and thickness of $\mathrm{ZnO}$ nanolayers

\begin{tabular}{ccc}
\hline Sample & Diameter $(\mathbf{n m})$ & Thickness $(\boldsymbol{\mu m})$ \\
\hline CBD & 89.41 & 1.80 \\
HT- 1 & 81.28 & 0.84 \\
HT-2 & 68.83 & 0.96 \\
\hline
\end{tabular}

The structural analysis of $\mathrm{ZnO}$ layers were carried out using $\mathrm{x}$-ray diffraction. Figure 3 shows the diffractograms of the layers. All peaks were confirmed with ICSD no 98-016-2843. The highest peaks were found in (002) plane. Thi condition indicates that most of the nanorods were grown vertically along the $c$-axis, which correlates with Fig. 1 and Fig. 2 previously presented. The estimation of the average crystallite size of the wurtzite phase in samples was performed using Scherrer's formula (Venkateswarlu, Chandra Bose, \& Rameshbabu, 2010). It is shown in Table 2 that the $\mathrm{ZnO}$ layers have the crystallite size around 56 to $59 \mathrm{~nm}$. The values were quite similar, which indicates that the treatments conducted during research were not giving significant effect on the crystallite sizes. However, HT-2 treatment resulted lattice parameters value which is very close to the bulk $\mathrm{ZnO}$, ie. 3.25 and $5.20 \mathrm{~nm}$, for $a$ and $c$ parameter, respectively.

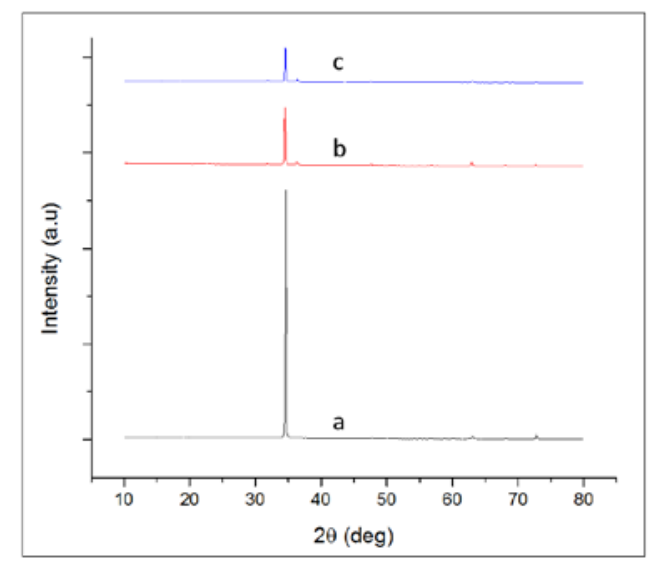

FIGURE 3. Cross-sectional view of ZnO layer on ITO with magnification of 40.000x a) as-grown with CBD method, b) after HT-1 treatment, c) after HT-2 treatment

TABLE 2. Crystallite sizes and lattice parameters of $\mathrm{ZnO}$ nanolayers

\begin{tabular}{|c|c|c|c|c|}
\hline \multirow{2}{*}{ Sample } & \multirow{2}{*}{ Crystallite size (nm) } & \multicolumn{3}{|c|}{ Thickness (nm) } \\
\cline { 3 - 5 } & & $\mathbf{a}$ & $\mathbf{c}$ & $\mathbf{a} / \mathbf{c}$ \\
\hline CBD & 59.57 & 3.18 & 4.99 & 1.57 \\
\hline HT-1 & 57.52 & 3.22 & 5.19 & 1.61 \\
\hline HT-2 & 56.37 & 3.26 & 5.22 & 1.60 \\
\hline
\end{tabular}

As a direct band-gap semiconductor, $\mathrm{ZnO}$ had an absorption coefficient $(\alpha)$ obeying the following relation for high photon energies (hv) (Ozdal et al., 2015; Pantoja Enriquez, Mathews, Pérez Hernández, \& Mathew, 2013):

$$
\alpha(h \vartheta)=A\left(h \vartheta-E_{g}\right)^{1 / 2}
$$


where $E_{g}$ is the optical band-gap of thin film, and A is a constant. Near the absorption edge, $\alpha$ can be expressed as:

$$
\alpha=-\frac{\operatorname{Ln}(T)}{d}
$$

where $T$ is transmittance and $d$ is the thickness of $\mathrm{ZnO}$ layer. The band-gap of the $\mathrm{ZnO}$ layers was calculated from the linear fit to the linear portion of the $(\alpha h v)^{2}$ vs $h v$ plot, and was shown in Fig. 4. From the figure, it can be assumed that $\alpha$ is closely related to the $\mathrm{ZnO}$ layer's thickness. Increasing thickness will reduce the transmittans of the layer, hence producing lower base line in the tail of $(\alpha h v)^{2}$ vs $h v$ plot.

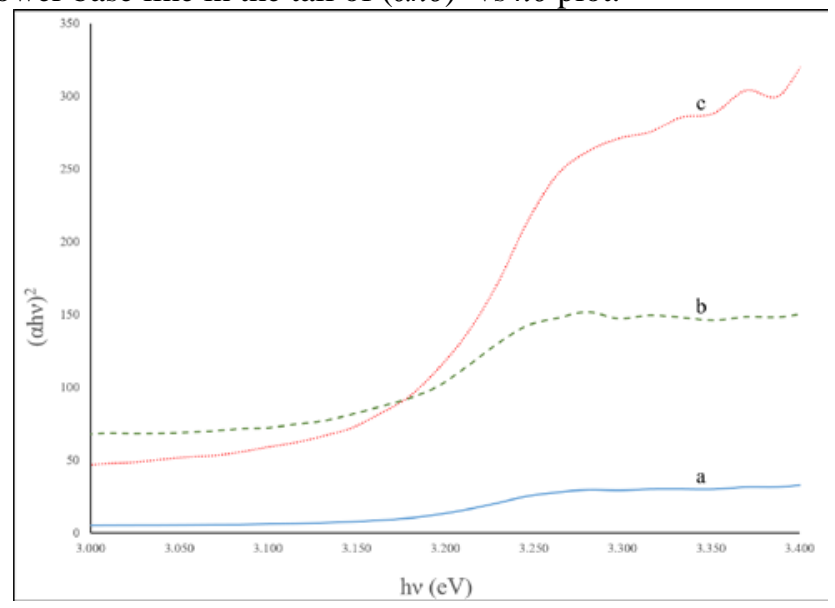

FIGURE 4. Eg value of ZnO layer on ITO a) as-grown with CBD method, b) after HT-1 treatment, c) after HT-2 treatment

TABLE 3. . Band-gap energies of $\mathrm{ZnO}$ nanolayers

\begin{tabular}{cc}
\hline Sample & Band-gap energy $\left(\mathbf{E}_{\mathbf{g}}, \mathbf{e V}\right)$ \\
\hline CBD & 3.16 \\
HT-1 & 3.15 \\
HT-2 & 3.16 \\
\hline
\end{tabular}

All $\mathrm{ZnO}$ layers were found to have similar band-gap energy. This can be related to the crystallite presented in Table 2. As mentioned previously, the difference in hydrothermal treatments did not provide significance influence on the structural parameters. However, HT-2 treatment developed the sharpest gradient, as shown in Fig. 4. This can be understood as a consequence of relation between $\mathrm{ZnO}$ layers thickness and transmittance. Hence, it is assume that $\mathrm{ZnO}$ layer after HT-2 treatment has the highest transmittance among all the $\mathrm{ZnO}$ samples.

\section{CONCLUSIONS}

High-quality oriented ZnO layers were successfully grown on ITO glass. To enhance the alignment and structural property, hydrothermal process was conducted. The strucural and optical properties of the layers were calculated and determined afterwards. Result showed that the hydrothermal process with the addition of $\mathrm{N}_{2}$ gas pressure (HT-2 treatment) has given the best layer, with average diameter, crystallite size, and band-gap energy of $68.83 \mathrm{~nm} ; 56.37 \mathrm{~nm}$; and $3.16 \mathrm{eV}$, respectively.

\section{ACKNOWLEDGMENTS}

This research was conducted under research grant from Islamic Development Bank - Universitas Sultan Ageng Tirtayasa (IDB-Untirta), with contract number 356/UN43.9/PL/2017.

\section{REFERENCES}

Duan, X., Chen, G., Guo, L., Zhu, Y., Ye, H., \& Wu, Y. (2015). A template-free CVD route to synthesize hierarchical porous ZnO films. Superlattices and Microstructures, 88(October), 501-507. https://doi.org/10.1016/j.spmi.2015.10.010

Hong, J.-I., Bae, J., Wang, Z. L., \& Snyder, R. L. (2009). Room-temperature, texture-controlled growth of ZnO thin 
films and their application for growing aligned ZnO nanowire arrays. Nanotechnology, 20(8), 085609. https://doi.org/10.1088/0957-4484/20/8/085609

Jo, J. H., Hur, T., Kwak, J. S., Kwon, D. Y., Hwang, Y., \& Kim, H. K. (2005). Effects of Oxygen Pressure on the Crystalline of ZnO Films Grown on Sapphire by PLD Method. Journal of the Korean Physical Society, 47(September), S300-S303.

Lizama-Tzec, F. I., Garcia-Rodriguez, R., Rodriguez-Gattorno, G., Canto-Aguilar, E. J., Vega-Poot, A. G., HerediaCervera, B. E., ... Oskam, G. (2016). Influence of morphology on the performance of ZnO-based dyesensitized solar cells. RSC Advances, 6(44), 37424-37433. https://doi.org/10.1039/C5RA25618F

Ozdal, T., Taktakoglu, R., Ozdamar, H., Esen, M., Takci, D. K., \& Kavak, H. (2015). Crystallinity improvement of ZnO nanorods by optimization of low-cost electrodeposition technique. Thin Solid Films, 592, 143-149. https://doi.org/10.1016/j.tsf.2015.09.013

Pantoja Enriquez, J., Mathews, N. R., Pérez Hernández, G., \& Mathew, X. (2013). Influence of the film thickness on structural and optical properties of CdTe thin films electrodeposited on stainless steel substrates. Materials Chemistry and Physics, 142(1), 432-437. https://doi.org/10.1016/j.matchemphys.2013.07.043

Shao, C., Chang, Y., \& Long, Y. (2014). High performance of nanostructured $\mathrm{ZnO}$ film gas sensor at room temperature. Sensors and Actuators, B: Chemical, 204, 666-672. https://doi.org/10.1016/j.snb.2014.08.003

Shinde, S. S., Bhosale, C. H., \& Rajpure, K. Y. (2013). Solar light assisted photocatalysis of water using a zinc oxide semiconductor. Journal of Semiconductors, 43(4), 043002 1-4. https://doi.org/10.1088/16744926/34/4/043002

Vanalakar, S. A., Patil, V. L., Harale, N. S., Vhanalakar, S. A., Gang, M. G., Kim, J. Y., ... Kim, J. H. (2015). Controlled growth of $\mathrm{ZnO}$ nanorod arrays via wet chemical route for NO2 gas sensor applications. Sensors and Actuators B: Chemical, 221(2), 1195-1201. https://doi.org/10.1016/j.snb.2015.07.084

Venkateswarlu, K., Chandra Bose, A., \& Rameshbabu, N. (2010). X-ray peak broadening studies of nanocrystalline hydroxyapatite by Williamson-Hall analysis. Physica B: Condensed Matter, 405(20), 4256-4261. https://doi.org/10.1016/j.physb.2010.07.020

Yang, J., Wang, Y., Kong, J., Jia, H., \& Wang, Z. (2015). Synthesis of ZnO nanosheets via electrodeposition method and their optical properties, growth mechanism. Optical Materials, 46, 179-185. https://doi.org/10.1016/j.optmat.2015.04.016 